\title{
LITERATURA Y PRENSA: LA COLUMNA DE ESCRITORES EN CHILE ${ }^{1}$
}

Literature and the press: the writer's column in Chile

\author{
Jaime Galgani Muñoz*
}

Resumen

El artículo desarrolla algunas reflexiones teóricas acerca de las características de la presencia de los escritores en el periodismo durante los siglos XIX y XX como autores de columnas de opinión asociadas a la crítica cultural. En segundo lugar, presenta una visión panorámica de la evolución del género en Chile en el mismo período y, finalmente, destaca el trabajo, como columnistas, de algunos de sus principales exponentes.

Palabras clave: Columna literaria, Columna cultural, Columna de opinión, Modernidad, Prensa y literatura.

Abstract

This article offers theoretical reflections on authors' presence in journalism -and their opinion columns on topics related to cultural critique- during the XIX and XX centuries. The article presents an overview of the evolution of Chilean journalism during the same period and, finally, highlights some of the period's leading pieces and columnists.

Key words: Literary column, Cultural column, Opinion column, Modernity, Press and literature..

\section{INTRODUCCIÓN}

El presente artículo recoge las reflexiones que inspiraron una investigación acerca de las relaciones entre escritores y prensa. Se ha establecido que uno de los espacios más privilegiados de dicha relación es el que corresponde a "la columna de opinión" en el periódico, con sus distintas variedades: artículo, columna cultural, crónica, etcétera. En ella aparece la voz y manifestación del escritor que se hace, a su vez, portador de un sentir valorativo que el lector le asigna confiriéndole autoridad para emitir opiniones respecto de los más variados temas, aunque, evidentemente, no sea experto en ninguno de ellos. De este modo, el escritor participa en el periódico como actor social opinante.

\footnotetext{
${ }^{1}$ Este artículo forma parte de las investigaciones del proyecto Fondecyt No 1130400 , "Literatura chilena y proyecto cultural en revistas de inicios del siglo XX (1900-1910)". Está basado en la ponencia "Columna literaria en Chile en el contexto de la modernidad de inicios del siglo XX" presentada en el X Congreso de la AEELH, Letras libres de un repertorio americano: historia de las revistas literarias, Cartagena, España, 4-7 de septiembre de 2012, y la ponencia "The writer's column in the history of the Chilean press: fundamental milestones”, presentada en el congreso Bridges across culture, Perugia, Italia, 27-30 de junio de 2013.
} 
En las últimas décadas se ha relevado con mayor notoriedad el análisis del género de opinión en los estudios literarios chilenos, enfocándose principalmente en la producción de columnistas contemporáneos destacados. Algunos estudiosos se han preocupado de la historia del artículo de opinión en su desarrollo durante el siglo XIX y algunos períodos del siglo XX. El período de entresiglos, sin embargo, suele verse más descuidado.

En este trabajo, después de proponer una problematización de la cuestión teórica en cuanto al género, se presenta una visión panorámica tentativa respecto de lo que sería una historia global de la crónica en Chile. Los tramos históricos han sido determinados teniendo en cuenta la propuesta de las tres constelaciones de José Joaquín Brunner. Como se verá, allí propongo algunas subdivisiones y extensiones, teniendo como fin demostrar que la situación del escritor en la prensa ha respondido a tres momentos fundamentales: hegemonía del escritor en la prensa (1812-1880), el escritor como principal actor opinante (1880-1990), desarrollo maduro de la columna de opinión en donde el escritor comparte con otros profesionales el ejercicio del género (1990 hasta nuestros días). Finalmente, se presentan algunos nombres de columnistas importantes de reconocer por cuanto afianzadores del género.

\section{LA COLUMNA PERIODÍSTICA Y SUS RELACIONES CON LA LITERATURA}

Se podría decir que el columnismo surge en Chile con el nacimiento de la prensa, el día 13 de febrero de 1812, cuando Camilo Henríquez, el fraile de la buena muerte, fundó La Aurora de Chile, primer periódico y primer texto impreso producido en nuestro país a dos años de la primera declaración de Independencia. Su programa era "construir los valores de la nueva nación chilena y conformar su identidad".

Sin embargo, compartiendo un desarrollo similar a otros países latinoamericanos e, incluso, al que tuvo en España, el género en cuestión experimentó sucesivos cambios en la historia de las relaciones entre la literatura (o mejor dicho entre los creadores de literatura) y el periodismo.

Según Grohmann, el columnismo, aun siendo un "género en gran medida nuevo en las letras españolas, [es] un género heredero [...] de fuentes autóctonas y de una rica tradición de simbiosis entre literatos y prensa" (2). Morán Torres postula que "la columna actual responde a lo que en el viejo periodismo era el artículo de un colaborador fijo, denominándose al que antes se llamaba articulista" (165). Grohmann indica que la columna actual, en España, se relaciona con el género romántico del costumbrismo, el que nace en los periódicos que acogen los artículos o "cuadros" de costumbres, en su parte amena, la parte inferior de la primera página separada por una línea de la sección política" (2), lo que indica, desde ya, la cualidad relativamente autónoma del género respecto de la discusión más explícitamente coyuntural. En España, los columnistas del siglo XIX fueron escritores. Más aún, lo eran todos los que ejercían el oficio del periodismo o, mejor dicho, intelectuales que dirigían la escena social desde varios ámbitos del desarrollo cultural. Ellos eran, según 
la circunstancia, los que producían textos poéticos, los que discurseaban en el Ateneo, los que dictaban clases en las instituciones educativas, los que escribían en los periódicos, los que dictaminaban sobre leyes y dirigían la escena pública de naciones que, sobre todo en América, estaban en proceso de construcción. Y, así como en Chile se destacan nombres como Alberto Blest Gana, Camilo Henríquez y Victorino Lastarria, en España hay notables escritores colaborando en los periódicos (Mariano José de Larra, Gustavo Adolfo Bécquer, Ramón de Campoamor, Juan Valera, Benito Pérez Galdós y Leopoldo Alas).

La diferencia que tiene la columna literaria con lo que posteriormente, en el siglo $\mathrm{XX}$, vendría a ser la columna de espectáculos, la columna deportiva o de crónica roja, está precisamente perfilada por estos escritores del siglo XIX, quienes, a ambos lados del Atlántico, se constituyen en artífices de un cierto "protocolumnismo" que se manifiesta en su "profunda preocupación por la utilización de la lengua, su concepción del articulismo como un género literario, la primacía concedida al estilo y los recursos retóricos, la ficcionalización de la realidad y del 'yo', y su empleo de la parodia, la sátira, el humor y el ridiculum en general con fines críticos" (Grohmann, 2). Características todas que están presentes en las columnas decimonónicas y que determinan parte del perfil del género hasta nuestros días. Ellas dan cuenta que, más allá de la cuestión de que se trata, la presencia del escritor en el periódico no está determinada por el "tema", sino por el "estilo". Esto lo demuestra el hecho que dicho estilo prevaleció por sobre las contiendas políticas que configuraban el mapa temático fundamental de naciones que se encontraban en su época fundacional.

El aserto de María Cruz Seoane respecto de que "puede afirmarse sin exageración que el ámbito natural del escritor es el periódico más que el libro" ( $\mathrm{Ca}$ literatura, 18) viene a confirmar el hecho de que el escritor nace a la luz en el periódico, sobre todo teniendo en cuenta las limitaciones que el mercado productor ofrecía a los creadores del siglo XIX para publicar libros y la naturaleza misma del periódico como espacio de exposición y reconocimiento (legitimación) del creador al interior de la escena cultural. En el mismo sentido, Seoane afirma que "hasta época relativamente reciente, las historias de la literatura no se ocupar[o]n de la prensa, pese a que en periódicos y revistas se han gestado todos los movimientos literarios contemporáneos, $\mathrm{y}$ han visto por primera vez la luz muchas obras antes de convertirse en libro" ( $E l$ periodismo, 23).

La formación de la "columna" en su sentido moderno tiene su origen en la evolución vivida hacia finales del siglo XIX y comienzos del XX, caracterizada por "la división del trabajo, la profesionalización del periódico y la especialización de la prensa capitalista [que] conducen a la necesidad de diferenciar las distintas voces que componen el periódico" (Grohmann, 2). Es así que, si antes "el artículo firmado hacía también las funciones de editorial", en el periodo señalado, comienzan a distinguirse voces: "la de la propia empresa, a través de la editorial, y la de los periodistas y 
colaboradores, a través de otros géneros de opinión, como la columna" (citando a Hidalgo).

En concordancia con el positivismo imperante en la modernidad que tardíamente llega a América, se genera la demarcación de espacios que se definen de manera clara al interior del periódico, dominados por el llamado "mito de la objetividad". En ese contexto, la columna de escritores nace en propiedad, tal como se la conoce ahora, es decir, como un género de opinión que se separa de otros que dan cuenta de la "noticia":

Concreta y paradójicamente [...], el nacimiento de la columna está relacionado con la progresiva despersonalización del periódico y el editorial, con su paso del punto de vista de la primera persona singular a la primera persona del plural, del "yo" del director y redactor al "nosotros" del colectivo de la redacción o la empresa entera y con la diferenciación de los distintos textos que componen el periódico. La columna, un género en un principio análogo al editorial, surge cuando este pierde su carácter personal, y se define precisamente por ser un texto firmado por una persona, como antes el editorial, una expresión de una visión del mundo muy personal, una voz individual (Grohmann, 2).

Grohmann también contribuye a agrupar los distintos elementos que dan cuenta del valor de la columna, destacándose su posibilidad de proporcionar "un tono distinto al tenor dominante de las malas noticias [...] dando un toque ligero a la seriedad prevaleciente", de "crear controversias", de "informar entreteniendo o entretener informando", ofrecer "una mirada, un punto de vista y estilo distinto que el lector aprecia y a través del cual aprende o con el cual se identifica", y se constituye por último en una especie de "mediador entre el lector del periódico y la realidad", la que es filtrada por él e interpretada (3). Así, se puede postular la tesis de que, dentro de la necesaria temporalidad y de la naturaleza efimera del quehacer periodístico, la columna de escritores asume la cualidad de lo menos pasajero; no por la vigencia de los asuntos que trata, sino por la forma literaria, el estilo, y la forma de comunicar de su autor.

León Gross reflexiona acerca de la identidad del género frente al problema de la hibridación periodístico literaria afirmando que

no se trata de considerar que la columna de análisis y la columna literaria son dos territorios aislados, respectivamente propios del Periodismo y la Literatura, sino dos soluciones coherentes para alcanzar el objetivo común de este género periodístico; de ahí que pueda hablarse de "artículos de persuasión argumentativa" y "artículos de persuasión ingeniosa" [no perdiendo de vista] que la persuasión opera en tres grados: docere, delectare y movere (8).

El literato transfiere a la columna su "virtud de orador" que "engendra delectatio", y por tanto además sirve a la causa, a lo aptum esencial del discurso. El ornatus formal, por consiguiente, no constituye aquí un capricho poético sino un recurso de notable importancia en el objetivo persuasivo, que es lo característico del columnismo (León, 8). 
En síntesis, las relaciones entre el periodismo y la literatura ofrecen dos vertientes de análisis presentadas aquí de forma suscinta: el proceso histórico de acercamiento, de hibridación y de demarcación, en primer lugar, y las características del género determinadas por el objetivo de crear una persuasión motivadora e ingeniosa, para lo que se vale de las propiedades retóricas propias del escritor.

\section{COLUMNA CULTURAL DE ENTRE SIGLOS}

La producción de columnas culturales de los escritores escogidos para este estudio está inscrita en el desarrollo de la modernidad correspondiente a las últimas décadas del siglo XIX y las primeras del siglo XX. Se entiende dicha modernidad desde la óptica de un sistema de representación destinado a aprehender la situación del hombre del fin de siglo latinoamericano como la de quien experimenta la crisis del sistema estable que caracterizó gran parte de los proyectos fundantes que dominaron el concierto político-cultural decimonónico de nuestras repúblicas. En este contexto, según lo expresa Rotker, la preocupación dominante ya no es "conformar un ser nacional a través de la literatura" (139) sino, precisamente, dar cuenta de esa crisis y de las esperanzas que naturalmente la complementan. Modernidad significa el redescubrimiento, "en el lenguaje y la experiencia cotidiana [de una] nueva relación entre los hombres, la naturaleza y el interior de cada cual" (139-140). Dicha relación supone el desafío de "construir un nuevo hombre" en una época desmembrada que, al decir de Martí, corresponde al tiempo de las "vallas rotas", en sustitución de aquel otro, anterior, que fue el tiempo de las "vallas alzadas" (introducción al Poema del Niágara).

La modernidad, según Julio Ramos, se inserta en América como un proceso de desautorización del "saber decir", modelo propio de los autores del siglo XIX. El escritor moderno discute la modernidad misma a la que pertenece por cuanto proyecto de Estado, instalándose en ella desde una posición crítica. La modernidad es contradictoria y plural. Octavio Paz la explica como una tradición de rupturas. "Lo moderno no se caracteriza únicamente por su novedad, sino por su heterogeneidad". Esta característica del período faculta la comprensión de la heterogeneidad discursiva, especialmente con el desarrollo del periodismo. Gracias a él es posible acceder a un cuerpo textual vasto, donde poco a poco se van observando ciertos discursos que generan la incursión de la diversidad temática, polémica y fragmentaria, a la vez que la señalización de distintas posiciones sectoriales, así como de nuevas concepciones del tiempo y de la historia (Domínguez Rubalcava).

Período de cambios a gran escala, la modernidad, para Martí, supone un dinamismo que genera incertidumbre en una vida que resulta ser fragmentaria, vertiginosa e imperfecta. Duda, transición y asombro, desestabilización de grandes proyectos, configuran el nuevo escenario en que se mueve el escritor.

En este contexto, Martí señala que "el lugar de las ideas es el periodismo" (Poema del Niágara). He aquí el espacio apto para vincularse con la nueva concepción, "el espacio de lo no permanente, de la comunicación, del aporte del dato 
actualizado, de los públicos mayoritarios, del inquirir y no establecer" (Rotker, 142).

Lo que corresponde a un nuevo soporte comunicacional, es decir, el diario, en oposición a las monumentales obras literarias del siglo XIX, corresponde también a una nueva concepción de la escritura, la que no puede ya aspirar a la ambición ordenada de un sistema de representación integral, monolítico, incuestionable y portador de verdad. La nueva escritura debe ser permeable a la irrupción de una vida que, en su impertinencia, acosa desde los más diversos frentes: el arte, la ciencia, la tecnología, el advenimiento de las masas, la educación, las progresivas y sectoriales luchas sociales, la creciente interconexión en el ámbito de las comunicaciones. Un individuo de a mediados del siglo XIX vivía en un mundo que podría ser más precario, pero sí más estable; el escritor de entonces podía acometer proyectos de largo aliento y sabía que el mundo que lo había precedido no cambiaría mucho en su futuro inmediato. El hombre finisecular, en cambio, inmerso en el clima espiritual que le ofrece el modernismo (que es la faz estético-espiritual de la modernidad), sabe que el tema del que escribe hoy cambiará probablemente mañana. La escritura, entonces, debe dar cuenta de esa inminencia; y nada más apto para ello que el soporte periodístico.

"El escritor [moderno] interroga lo inmediato e interroga a la vez su subjetividad" (Rotker, 143). Esta es una característica radical de la época, ya que la inseguridad e inestabilidad de los sistemas conduce a la certeza de que solo lo subjetivo y vivido aparece como seguro. No hay confusión con el romanticismo, pues la experiencia modernista y las operaciones constructivas del yo que le suceden no coinciden con la óptica confesional y personalista del romanticismo, sino que "es un yo que quiere asumir en sí el universo, un yo colectivo que no expresa la individualidad sino el alma del mundo" (Rotker, 144). El escritor moderno no se concentra en su intimidad (como lo hacía el romanticismo), sino que subjetiviza los múltiples estímulos del mundo exterior para devolverlos a él como un caleidoscopio de miradas y resonancias. Su proyecto no es una escritura de evasión, sino la personalización de la vertiginosidad de estímulos que vienen del entorno. Y, si el soporte propio del poeta romántico era su cuaderno escondido de notas, el soporte del escritor moderno será, por cierto, el periódico, pues en él confluyen todos los elementos mencionados: fragmentariedad, discursos yuxtapuestos, dinamismo, conciencia del tiempo que fluye, heterogeneidad. Aunque parezca contradictorio, en esta época, el escritor encuentra un lugar muy propio entre noticias, reportajes y publicidad, pues el periodismo, después de haber evolucionado en la línea del reporter, a fin de comunicar objetivamente los acontecimientos que llegaban por el "cable", articula espacios de expresión personal concedidos a hombres reconocidos en su autoridad literaria. El público espera, requiere y necesita de la expresión personal (por eso se le llamó también periodismo de opinión) de aquellos a quienes ha conferido valor. Ese es el lugar de la columna que redactan diversos escritores. Siendo "pequeñas obras fúlgidas" -como las llamó Martí-, en ellas es posible percibir la variabilidad del mundo, de sus transiciones y de los acentos que lo configuran. 


\section{LA COLUMNA DE ESCRITORES EN LA HISTORIA DE LA PRENSA CHILENA: PRINCIPALES HITOS}

Para comprender las relaciones entre la prensa y los escritores en Chile es necesario considerar una propuesta de contexto que permita subclasificar el amplio período de nuestra historia republicana (más de 200 años) atendiendo a los diversos ciclos político-culturales y a los movimientos que los explican. Para esto, de manera provisoria resulta útil el análisis que en su momento ofreciera el cientista social José Joaquín Brunner (1985). En efecto, él habla de tres constelaciones: la constelación tradicional de élites (1810-1930), la constelación moderna de masas (1930-1973) y la constelación moderna de elites (1973-1985). Esta última es perfectamente aplicable en su análisis hasta 1990, período en que comienza un nuevo desarrollo políticosocial, debido al término de la dictadura militar y el regreso a la democracia, situación que se mantiene hasta hoy. El primer período (1810-1930), según lo presenta José Joaquín Brunner, merece una subclasificación, ya que son fácilmente identificables dos procesos en él. Uno que va desde 1810 a 1880 y otro que se extiende desde 1880 a 1920.

4.1. 1810-1880: Construcción de la nación en el contexto de la dirigencia tradicional de élites

Durante este período, el mercado cultural se caracteriza por estar formado de manera exclusiva por letrados, todos pertenecientes a la élite social del país. La población educada corresponde a una minoría y los centros de difusión cultural se concentran sobre todo en las principales ciudades (Santiago de Chile, en primer lugar). El campo cultural está dominado por los circuitos oligárquicos y la Iglesia católica, se propugna la alta cultura, y predomina la figura del hombre letrado, quien, desde su situación de clase, domina la escena social prácticamente sin diferenciación de oficios (Brunner, 64-65). Es posible identificar dos generaciones importantes en el período: la de 1810 y la de 1842, en donde figuran los nombres más significativos en el proceso de construcción de nación al que se sentían convocados: fray Camilo Henríquez (fundador del primer periódico nacional, La Aurora de Chile, en 1812), Manuel de Salas, José Victorino Lastarria, Francisco Bilbao y Andrés Bello, entre otros. "Todos ellos conforman una comunidad de lectores en la medida en que comparten códigos, valores, supuestos e ideales, lo que incide en sus prácticas lectoras y en la valoración de ciertos autores o de uno u otro título, preferencias que se manifiestan en el periodismo de ideas, posterior a la Independencia" (Subercaseaux, 158). Sus inspiraciones están determinadas por el pensamiento ilustrado francés, por la razón como ordenadora del conocimiento, la libertad como valor supremo y la convicción de que la República es el sistema ideal de gobierno. Respecto de la literatura, tienen una convicción de que ella debe tener un fin edificante, e iluminar el 
conocimiento, en el entendido de que toda expresión escrita contribuye al ideal de civilización que los anima. Se saben artífices de un tiempo fundacional en el que les corresponde configurar una "idea" de la nación antes que ella siquiera llegue a tener existencia plena (Subercaseaux, 158-166). Ese esencialismo político-cultural permite configurar un cuadro en el que prácticamente es imposible escindir la diferencia entre el escritor productor de literatura y el escritor que escribe en los periódicos; todavía no hay un verdadero periodismo de opinión, sobre todo si se considera que la incursión de los letrados en el periodismo tiene un valor profundamente rector.

\subsection{0-1930: Proceso de transición y autonomización del campo cultural}

El período siguiente, aún dominado por las mismas características propias de la constelación tradicional de élites, permite señalar una transición significativa de los posicionamientos que adopta la clase oligárquica respecto de su participación en el campo cultural. En la década de 1880-1890 se desarrolla en los salones del Palacio presidencial varias tertulias animadas por Pedro Balmaceda Toro, hijo del entonces Presidente de la República. En dichos encuentros participaban jóvenes intelectuales letrados, miembros también de la oligarquía social, con la presencia activa de un joven nicaragüense recién llegado a nuestro país: Rubén Darío. Ellos contribuyen a la incorporación de escritores europeos no leídos hasta entonces entre nosotros y participan también en los periódicos del momento. La lectura de Tolstoi, Zola, Flaubert, entre otros, genera una nueva visión de mundo que va a influir en la creación de una generación de escritores y columnistas más empoderados de una función crítica respecto del modelo de nación, además de aportar con el desarrollo de las "bellas letras", concepto que asigna a la literatura no solo un rol didáctico, sino, eminentemente, un valor estético. Poco a poco, y sobre todo tras los acontecimientos de $1891^{2}$, se comienza a gestar un campo cultural más autónomo respecto de la hegemonía del poder; en él participan incluso algunos exponentes destacados que provenían de otras capas sociales. Augusto D'Halmar y Baldomero Lillo son algunos de los más connotados exponentes de comienzos del siglo XX. Augusto D'Halmar, por ejemplo, siendo muy joven, ya publica sus columnas en los periódicos locales, llegando a ser un acabado columnista durante varias décadas del nuevo siglo. Sus colaboraciones en los periódicos dan evidencia de un lector culto, ya consagrado por sus obras literarias, que se permite opinar de los más diversos aspectos de la vida

\footnotetext{
${ }^{2}$ Con todo, varios historiadores coinciden en que la Guerra Civil de 1891 marca un antes y un después en nuestra prensa. ¿Qué significa esto? Simplemente, que la política deja de ser la preocupación única de los lectores. Como lo explica Gonzalo Vial en su Historia de Chile: "Progresivamente se iba disipando el entusiasmo público por la polémica doctrinaria. Y aparecían intereses nuevos: el deporte para sus cultores; las leyes y los reglamentos para la burocracia en desarrollo y para el núcleo asimismo creciente que formaban los afectados por una legislación cada vez más compleja; el cable extranjero para las colonias foráneas; el folletín, la moda, lo doméstico, la vida social y el cine para las mujeres; el arte y la cultura para los intelectuales; la publicidad para el comercio, etc.” (Citado por Matus, en línea).
} 
cotidiana: pintura, música, política, acontecimientos bélicos, problemas sociales, etc. Con su participación, queda bastante definida la orientación del escritor-columnista, un sujeto que se siente más autónomo y que no asume su tarea como constructor de un proyecto nacional sino como un opinante culto, poseedor de una autoridad conferida por el público lector que, gracias a las políticas educativas imperantes, comienza a ser cada vez más numeroso.

4.3. 1930-1973: Interrelación madura entre prensa y escritores, en el contexto de la especialización profesional (constelación moderna de masas)

La constelación moderna de masas, señalada por Brunner desde 1930-1973, pero quizás ya iniciada, en sus aspectos fundamentales, algunos años antes, presenta un mercado cultural extenso, estratificado, en donde se margina solamente al analfabeto rural. Se hace presente en una red nacional de carácter urbano y responde a un modelo de amplia difusión educativa, con significativos aumentos en los niveles de escolarización y amplio desarrollo de los medios periodísticos. El campo cultural está caracterizado por estar formado por las capas medias educadas, por favorecer la alta cultura con base profesional, por responder al modelo institucional correspondiente al sistema intelectual moderno, por favorecer la alta competencia por el control de los medios, por la participación de intelectuales especializados, profesionales y con alta orientación pública y por la movilización y diversificación además de un alto desarrollo de una clase media significativa (Brunner, 64-65).

Los escritores de este período participan ampliamente en la prensa con periódicas columnas culturales. Son sujetos culturales plenamente autorizados por el prestigio de sus publicaciones literarias. El periódico, a estas alturas, "se presenta como un especie de escritura (y de lectura), internamente regido por la discontinuidad entre los diversos textos que lo forman. Es pues un espacio regido por el fragmentarismo" (Morales, 66). En ese nuevo contexto, el escritor participa con su crónica, o su columna de opinión, en términos genéricos, participando de ese fragmentarismo, encontrándose con un lector que sabe distinguir, respecto de las distintas secciones del periódico, expectativas diferentes. Exponentes significativos de este período son Joaquín Edwards Bello y Jenaro Prieto.

\subsection{3-1990: Relación vigilada entre prensa y escritores (constelación moderna de élites)}

La constelación moderna de élites presenta un mercado cultural de masas segmentado, de acceso universal. El campo cultural está caracterizado por los medios masivos de comunicación, los circuitos de cultura oficial de mercado, por la competencia patrocinada dentro de ciertos cierres ideológicos, presencia de profesionales especializados con orientación privada, etcétera (Brunner, 64-65). La característica del período está dominada por el control de la censura dictatorial, decreciente pero no menos gravitante a medida que pasaron los años. Los rasgos 
generales del período están dominados por la ausencia de libertad de prensa, por el exilio que afectó a no pocos agentes culturales, entre ellos algunos escritores. La prensa oficial no facilitaba la presencia de opiniones disidentes, surgiendo varias revistas que asumieron este rol. Se llegó a una situación de "opinión secuestrada", como lo señala Álvaro Matus, quien postula que "[e]n las páginas de Apsi, Análisis, Cauce, Hoy, Pluma y pincel, Fortín Mapocho y La Bicicleta aparecieron las primeras voces disidentes a la dictadura de Pinochet" (Matus, en línea), advirtiendo que dichas publicaciones sufrieron a menudo la suerte de la suspensión y de la censura.

\subsection{0-2013: Desdibujamiento del rol del escritor como columnista cultural y aparición de nuevos agentes en la prensa de opinión}

Si se pudiera aventurar en la extensión de la clasificación de constelaciones que ofrece Brunner, habría que decir que la nuestra corresponde a una "constelación de masas postmoderna", caracterizada por un mercado cultural abierto a las masas, acceso universal a los medios de comunicación, con predominio de las recientes pero exitosas redes sociales, público más democratizado y segmentado por preferencias personales, con amplios niveles de escolarización pero con manifestación de una alta pugna por el acceso a la educación de calidad y gratuita para todos. El campo cultural responde a diversos agentes que participan de los diversos medios, globalización de la cultura, emergencia de voces subalternas, alta competencia, reivindicación de los derechos humanos y búsqueda de mayor transparencia económico-social.

En este contexto, ha tendido a desaparecer la voz del "escritor autorizado" como líder de opinión. Su rol ha sido desplazado por otros agentes de la vida cultural: sociólogos, políticos, economistas, periodistas, etcétera. Junto a ello, se suma la emergencia de la participación de miembros de la cultura popular que están en el comentario cotidiano de las clases medias y populares. La columna cultural, si bien sigue estando presente en los periódicos más prestigiados, no pocas veces es desplazada en importancia por el blog o la emergencia de nuevos medios de comunicación.

En conclusión, la historia de las relaciones entre escritores y prensa en Chile es posible de clasificar en cinco momentos clave. Un primer período (1810-1880) en que domina la idea del periodismo de ideas y en el que tiene lugar el hombre letrado, indistintamente político, jurista, economista y escritor; un segundo período (18801930) en que se comienza a gestar un campo cultural autónomo en que el escritor aparece cada vez más como un profesional de élite que se permite aparecer en los periódicos con sus columnas de opinión; un tercer período (1930-1973) en que se da un desarrollo más pleno de la autonomización de campo iniciada en el período anterior y en que el escritor es ya un agente altamente especializado, conocido eminentemente por su producción literaria y que se hace presente en el periódico como voz autorizada, como líder de opinión; un cuarto período (1973-1990) en que domina la censura político-cultural de la dictadura y pierde valor crítico la presencia 
de la columna cultural en los periódicos, desplazándose fundamentalmente hacia otros medios (revistas disidentes al régimen que sufren también los riesgos de la censura). Finalmente, un quinto período (1990-2013) en que la emergencia de la nueva democracia coincide con la nueva revolución de los medios de comunicación social, permitiendo la aparición de nuevos agentes de opinión al mismo tiempo que la pérdida de poder del periódico frente a otros vehículos comunicativos.

\section{ESCRITORES COLUMNISTAS EN CHILE}

Según Álvaro Matus, lo que cambia la escena chilena de entre siglos es "el fantasma de la objetividad" ${ }^{3}$, tal como lo planteaba Grohmann para España. Dicho proceso se materializó de forma antecedente con la publicación de los diarios $E l$ Ferrocarril y El Mercurio de Valparaíso, como "antesala de lo que sucedería en el siglo XX" (en línea) y de forma patente con la fundación de El Mercurio de Santiago, en 1900. Agustín Edwards Mac-Clure, su fundador, se preocupó de premunir su empresa periodística de los adelantos técnicos más avanzados que importó directamente desde Estados Unidos y de la visión periodística moderna que ya era norma en los países desarrollados de la esfera occidental, incorporando el pragmatismo necesario a un tipo de información que necesitaba dar evidencias de verosimilitud. Dicho proceso fue seguido también por otros fundadores, entre ellos Eliodoro Yáñez, quien fundó La Nación, periódico que "también adscribía a la tendencia norteamericana, privilegiando la información y titulando en forma más sintética" (Matus, en línea).

El nuevo escenario, entonces, difiere del periódico decimonónico en la importancia y centralidad que confiere a "la noticia". Aunque hubiera parecido una amenaza para el periodismo de opinión, se transformó, paradójicamente, en una oportunidad para mostrar al escritor opinante, columnista, articulista, desde una angulatura más independiente respecto de la línea editorial. Probablemente, desde entonces, fue necesario aclarar que el periódico no se identificaba necesariamente con las opiniones de sus columnistas. Es decir, el escritor sigue estando vinculado al periodismo, pero no gozando del poder que le confería su antigua situación, $\mathrm{y}$, recibiendo, a cambio, la legitimación que produce el valor autónomo que ofrece su estilo y la orientación que da a su trabajo opinante.

\footnotetext{
${ }^{3}$ En la historia del periodismo mundial han existido, según Richard Kapuscinski, dos escuelas: la anglosajona y la europea continental. La primera, nos dice el autor en Los cinco sentidos del periodista, tiene como fortaleza la objetividad: "La noticia que presenta los hechos tal como sucedieron debe presentarse separada del comentario que los interpreta desde un punto de vista determinado", afirma Kapuscinski, y agrega: "Cada diario que suscribe estos principios organiza a sus periodistas en dos categorías: los que escriben la noticia pura y dura y los columnistas". La corriente periodística europea continental, la de Francia o Italia, concibe los medios como un instrumento de los partidos y gobiernos. Como hemos visto, esta escuela es, a todas luces, la que dominó nuestra prensa durante la mayor parte del siglo XIX: la fuerza de los artículos radicaba no tanto en informar como en exponer las ideas del autor o del medio mismo" (Matus, en línea).
} 
En este nuevo paradigma destacaron escritores de gran valor. Quizás la figura más notable fue la de Joaquín Edwards Bello, novelista connotado que publicó, entre otros textos, El roto y La chica del Crillón. Fue columnista sobre todo en La Nación y en Los Tiempos. Álvaro Matus dice que escribió en torno a 12.000 columnas; más modesto en sus cálculos, Leonidas Morales postula que entre 4.600 y 4.800; en cualquier caso, todos atribuyen a Edwards Bello quizás la mayor producción de columnas periodísticas que se haya visto en el ambiente nacional. Alone destaca que "contra todos y a pesar de todos, Edwards Bello se hace leer y discutir apasionadamente. Existe con innegable vigor: posee en el estilo, en el simple modo de agrupar palabras, las imágenes y las frases, esa potencia eléctrica que no permite leer en frío" (citado por Matus). Edwards Bello fue ese intelectual-escritor que desde la columna desplegaba

[u]na sutil aspereza [que] se colaba entre tanto personaje que hacía aparecer y desaparecer de sus crónicas. Alérgico a cualquier eufemismo y siempre desenvuelto, el autor diseccionaba los valores y hábitos del país, llegando a decir, por ejemplo, que el chileno tenía la alegría "del incendio, de la demolición, del velorio". Denunciaba a los lateros, [...] se reía de la vocación litigante del chileno... (Matus, en línea),

e incluso se permitía desperfilar el oficio del escritor (aunque lo era él con toda propiedad) como la de un "bellaco disfrazado" y ensalzar el periodismo como una tarea de "utilidad pública". No cabe duda de que Joaquín Edwards Bello es una de las pruebas patentes de que "el fantasma de la objetividad" no destruyó el lugar del escritor en el periodismo, sino que permitió recolocarlo desde un lugar donde pudiera expresarse con menos compromiso y más libertad, pudiendo ejercer una influencia preponderante en los hábitos y la cultura de la nación. Sin duda que dicho modo de concebir la labor del escritor en la prensa permite enriquecer la naturaleza del periodismo, sustrayéndolo del reduccionismo positivista que lo limita a la "noticia" y comunicándolo con la vasta necesidad que los pueblos tienen de un discurso que, exhibiendo el calificativo de opinante, también reclama su participación en la ardua contribución por develar la siempre escurridiza "verdad".

Hubo otros destacados exponentes del columnismo en periódicos que, tal como Joaquín Edwards Bello, atravesaron varias décadas del siglo XX. Destacan, entre ellos Daniel de la Vega y Jenaro Prieto. Sin embargo, por lo que se refiere al período que cubre la primera mitad del siglo, merece ser destacado por su trabajo como columnista el escritor Augusto D'Halmar. Sus colaboraciones comenzaron bastante pronto, cuando se dice que tenía alrededor de 15 años, en algunas publicaciones menores. No obstante, es en 1900 cuando comienza a desarrollarse su participación como escritor columnista, en la revista Luz $i$ sombra y, posteriormente en Instantáneas de Luz i Sombra. Tenía, entonces, apenas 18 años y ya había sido calificado por Nadir (uno de los críticos de Luz i Sombra), como un "médico de almas" que posee "un bisturí [que] penetra tan hondo que a veces asusta". Dice que su 
"pintura realista lo convierte en un ser cruel. Zola, a la edad de Thomson (apellido real del autor), era acaso más humano o, más bien dicho, tenía más piedad con los heridos, los enfermos del pudridero humano" ( $\mathrm{N}^{\mathrm{o}} 28$, septiembre de 1900). Para el crítico Guillermo Muñoz Medina, "[a]sí como Cabrera lo fue de Pluma i Lápiz, Thomson llegó a ser el alma de Instantáneas" (227). En ella, junto a algunos de sus primeros relatos, escribe unas columnas que tienen por nombre "Potpourri" (comentarios generales de arte) y "Los 21", destinada a exponer semblanzas de escritores. El trabajo de D'Halmar responde a la tónica de los nuevos tiempos, pues va acompañado de la relación estrecha que establece con otros escritores y columnistas para presentar un trabajo que, de algún modo, representa el producto de las conversaciones de tertulia en torno a las preocupaciones y novedades del momento. Posteriormente, D’Halmar escribió en varios periódicos. Son de destacar sus colaboraciones en El Mercurio, en la revista Zig-Zag, en La Nación, La Unión, y otros. Uno de los periódicos en donde alcanza su madurez como columnista escritor fue Informaciones, diario madrileño donde publicó entre 1926 y 1931. Dichas columnas (más de 160 en total) ejemplifican la presencia del escritor moderno en la prensa. En efecto, allí se destaca que la valía del escritor en el periódico está dada por la presencia de un estilo que lo caracteriza. Así por ejemplo, cuando habla de la "fama y la celebridad", dice, con una ironía singular:

Fama y celebridad parecen ser sinónimos, y el propio diccionario no hace más distinción entre ellas que llamar a la celebridad fama grande. Sin embargo, en la práctica, muchos personajes célebres no han conseguido ser famosos, y muchos hombres famosos no han llegado a ser célebres (13 de agosto de 1928).

O cuando, para hablar sobre la situación de algunas regiones que padecen el flagelo del hambre, comienza con una breve frase:

[Hambre] Alguien me ha dicho que esta era una palabra que llenaba (5 de septiembre de 1927).

O cuando, hablando de Marco Aurelio, encierra en una breve introducción las cualidades del emperador y del pensador:

Marco Aurelio demostró que la púrpura imperial caía bien sobre la túnica del filósofo; pero aquellos eran otros tiempos, y él era, sobre todo, otro hombre, único, al cual le fuera dado conciliar la potestad máxima con la suprema sabiduría (10 de febrero de 1930).

Así, pues, en muchas de sus columnas, el peso del estilo está condensado en la primera frase, suficiente como para motivar al lector, interesado probablemente en las noticias del día, para continuar leyendo su propuesta y generando, quizás, el interés por seguir su crónica semanal, cuestión característica del columnista de crítica cultural. 
El estilo de D'Halmar también a veces se hace notar en la última frase o párrafo. Por ejemplo, cuando habla de los últimos días de Goya en Burdeos, termina su columna de este modo:

Iba obscureciendo. Don Francisco se despidió de esa corriente de agua que incesantemente llevaba hacia el mar sus tardas y tardías divagaciones y abrazó con los ojos el ámbito amado del cielo, que, ese sí, se albergaba en su pecho. ¡Poca cosa el hombre! Pero inestimable la pequeña partícula que destella e irradia en el fondo de su ser y que nada, ni la muerte ni la nada, conseguirán extinguir! (26 de abril de 1928).

Al comentar la crisis de Wall-Street, termina con la siguiente reflexión:

¿[...] ya que si "al que busca la Verdad lo demás le será dado por añadidura", al que la rehúya lo demás deba ser quitado? La aventura de Wall-Street hará más astutos o más audaces a los agiotistas, sin que, como decíamos, cristalice en ningún concepto de elevada moral, a cubierto de malversaciones. Y únicamente los dominios espirituales son inalterables. Quien vive solo para el pan, al perderlo pierde con él la vida o su razón de vivir; pero aquel que haya vinculado su existencia a la del espíritu, por el espíritu será salvo (16 de noviembre de 1929).

Lo que se hace ver en estos ejemplos es que "el estilo" es la materia fundamental, el hilo conductor de las diversas columnas. Hablando de una ciudad española, de una catedral, del cine y sus promesas, del Monasterio de El Escorial, de la crisis de Wall Street o de los últimos días de Goya, cualquiera sea el asunto tocado por el escritor, hay en su tratamiento una marca personal que lo distingue. Y, si en el caso de D'Halmar, es esa capacidad de arrancar una verdad trascendente al momento o a la oportunidad, en otros casos, será otro acento el que prevalezca, pero, en todos, sin duda, se hace notoria la capacidad de imprimir una nota personal que, de algún modo, es capaz de llegar a un público lector que se siente interpretado por ella.

Otro aspecto relevante en las crónicas de D'Halmar consiste en que supo entender lo que Martí había hecho notar respecto de que el periodismo es el lugar de las ideas. En esto, D’Halmar revela su condición de escritor moderno. No optó por la obra ensayística monumental, sino por simples columnas que, aparte de otorgarle el sustento cotidiano y mantener la vigencia de su nombre, le ofrecían un escenario donde sus ideas pudieran alcanzar algún grado de expresión.

Es conveniente hacer notar que el proyecto destinado a investigar las relaciones entre escritores y prensa en las primeras décadas del siglo XX, aparte de ahondar en la búsqueda de material y profundizar en el análisis de los columnistas más reconocidos, tiene como objetivo reconocer el aporte que, en la materia, hicieron algunos escritores menos recordados, quienes, no obstante, supusieron un desarrollo del género importante de relevar a la hora de estudiar las bases de la formación del campo cultural en Chile. Entre ellos, figura, en primer lugar, Joaquín Díaz Garcés, quien cumplió, durante varios años, funciones de dirección en El Mercurio, lo que no 
le impedía "escribir en el diario ya la página amplia de reconstitución histórica, en que solía aceptar la influencia de Georges d'Esparbès, ya la nota ligera, zumbona, donde se emparentaba con Larra por el afán de poner en solfa las costumbres sociales que le eran mejor conocidas" (Silva Castro, 352). Junto a sus escritos en El Mercurio y El Chileno, El Diario Ilustrado y otros, publicó el volumen titulado Páginas chilenas y Páginas de Ángel Pino. Exequiel de la Barra, por su parte, fue un destacado cronista en La Nación; "redactor de criterio ponderado y de límpido estilo que hace que sus escritos sean leídos con agrado e interés" (Valdebenito, 254). Rafael Maluenda Labarca, además de su producción literaria, publicó en La Ley, El Ferrocarril, El Diario Ilustrado, y en las revistas Zig-Zag y Sucesos. Daniel de la Vega Uribe, redactor y crítico teatral de El Mercurio de Santiago y de Las Últimas Noticias. "Poeta de alto vuelo lírico, figura entre los valores consagrados de nuestra literatura. Como periodista posee un estilo sobrio y ameno. Su prosa límpida, personalísima parece inspirada en su cosecha lírica. Sus comentarios periodísticos poseen valor perenne" (Valdebenito, 309-310). Nathanael Yáñez Silva, crítico de arte, autor teatral, colaboró como periodista a partir de 1905 en El Diario Ilustrado, La Nación, Los Tiempos y Las Últimas Noticias.

Todos estos escritores y otros más son parte de esa generación que ofrece al género "columna de opinión" un desarrollo empírico notable, participando de los periódicos mencionados. En ellos se leen sus colaboraciones con atención, en ellos se prolonga su labor escritural, en ellos se configura el nuevo modo de participar de los novelistas, dramaturgos e incluso poetas en el escenario cultural propio de inicios del siglo XX, el que, como se ha dicho, está marcado por la especialización de oficios, por la separación de secciones dentro del periódico, por la autonomización del campo literario, y por el efecto a que conduce la intermediación masiva de la prensa como espacio de comunicación entre creadores y un público lector cada vez más numeroso y anónimo.

\section{CONCLUSIONES}

Las relaciones entre el escritor y la prensa se desarrollan entre el siglo XIX y el $\mathrm{XX}$ siguiendo un proceso que va desde la presencia totalizante de los mismos, como hombres letrados, hasta la diversificación de las tipologías textuales asociadas al género periodístico. En un principio, el escritor está presente en todo el desarrollo del periódico. Ejemplo de ello es Camilo Henríquez. Más adelante, cuando el periódico deja de ser simplemente un instrumento ideológico al servicio de determinadas corrientes y asume el carácter positivista de la "objetividad", el periódico es absorbido por la centralidad de "la noticia", como factor principal de desarrollo. Aparece la página editorial y las diversas crónicas especializadas. En medio de ellas, la columna de opinión, desarrollada a menudo por escritores reconocidos por la sociedad, se formula como un subgénero emparentado en cierto modo con el ensayo, que no tiene las pretensiones científicas de una "demostración” y que solamente exige un papel, 
una pluma y una voz autorizada. En España hubo grandes columnistas que cultivaron este género (Unamuno, Azorín, Ortega y Gasset); en Chile destacaron, desde las primeras décadas, Augusto D'Halmar, Joaquín Edwards Bello, Jenaro Prieto y otros más. En ambos casos ellos son los primeros exponentes de un articulismo que ha tenido un gran desarrollo hasta nuestros días. Si en algún momento, con el desarrollo del periodismo objetivo, se temió que los escritores desaparecieran de la escena principal de la cultura, este desarrollo del "periodismo de opinión" echó por tierra dichos presagios. Lo que sí sucedió es que, convertido el periódico en el "nuevo lugar para la expresión de las ideas", el escritor pronto debió reorientar sus esfuerzos y adaptarse a los nuevos tiempos. Para el caso de América y de España, sirvió, sin duda, el testimonio de numerosos "protocolumnistas" pertenecientes al siglo XIX.

¿Qué explica el éxito del género? Varios teóricos han contribuido a concluir que no se debe sino a que la columna escrita por escritores comunica algo que les es propio y que es la tonalidad con que asumen los acontecimientos cotidianos. También contribuye el hecho de que el público lector, amenazado por el tono pesimista de la noticia diaria, necesita también encontrar un espacio donde se le permita identificarse con corrientes de opinión que le hagan posible acceder, en medio de la transitoriedad de lo fragmentario, a una cierta relativización de lo negativo, por medio de la parodia, a una cuota de trascendencia, por medio de la reflexión moral o espiritual, e, incluso, en ciertos momentos, a una intuición parecida a la verdad.

\section{Universidad Metropolitana de Ciencias de la Educación* Departamento de Castellano Av. José Pedro Alessandri 774, Ññ̃oa, Santiago (Chile) jaime.galgani@gmail.com}

\section{OBRAS CITADAS}

Brunner, José Joaquín. "Cultura y crisis de hegemonías". En Brunner, José Joaquín y Gonzalo Catalán. Cinco estudios sobre cultura y sociedad. Santiago de Chile: Ediciones Anaivillo, 1985: 13-68.

D’Halmar, Augusto. Informaciones. Diversas columnas escritas entre 1926 y 1931.

Domínguez Rubalcava, Héctor. La modernidad abyecta: formación del discurso homosexual en Hispanoamérica. Xalapa: Biblioteca U. Veracruzana, 2001.

Grohmann, Alexis. "La escritura impertinente". El género del columnismo de escritores contemporáneos (1975-2005). En Insula, Revista de letras y ciencias humanas, 703-704 (2005), Madrid.

León Gross, Teodoro. "La columna y lo literario como valor periodístico". El género del columnismo de escritores contemporáneos (1975-2005). En Insula, Revista de letras y ciencias humanas 703-704 (2005), Madrid. 
Martí, José. "Prólogo al poema del Niágara”. En Obras completas. La Habana, 1975 (1882). Matus, Álvaro. "Historia abreviada del periodismo de opinión en Chile”. Dossier. Revista de la Facultad de Comunicación y Letras. Número monográfico: Chile, país de columnistas. Santiago: UDP, 2009. Versión electrónica revisada con fecha 29 de abril de 2012. http://www.revistadossier .cl/detalle.php?BD=dossier_textos\&id dos $=5$ \&pags $=0$

Morán Torres, Esteban. Géneros del periodismo de opinión. Crítica, comentario, columna, editorial. Pamplona: Eunsa, 1988.

Morales, Leonidas. "Joaquín Edwards Bello: crónica y crítica de la vida cotidiana chilena". Revista Chilena de Literatura 74 (2009): 57-78.

Muñoz Medina, Guillermo. "La generación literaria de 1900 y Augusto Thomson", en Atenea 116 (1935): 223-241.

Nadir. "Nuestros colaboradores". Luz i Sombra. 28 de septiembre de 1900.

Rotker, Susana. La invención de la crónica. Buenos Aires: Ediciones Letra Buena, 1992.

Seoane, María Cruz y Sáiz María Dolores. Historia del periodismo en España, 3. El siglo XX: 1898-1936. Madrid: Alianza, 1998.

Seoane, María Cruz. "La literatura en el periódico y el periódico en la literatura". En Periodismo y literatura, ed. de Amelies van Noorwijk y Anke van Haastrecht. Amsterdam: Rodopi, 1977: 17-25.

Seoane, María Cruz. "El periodismo como género literario y como tema novelesco". En Literatura y periodismo. La prensa como espacio creativo, ed. de Salvador Montesa. Málaga. Congreso de literatura española contemporánea, 2003: 9-32.

Silva Castro, Raúl. Prensa y periodismo en Chile. Santiago de Chile: Universidad de Chile, 1958.

Subercaseaux, Bernardo. "Literatura y prensa de la independencia, independencia de la literatura". Revista Chilena de Literatura 77 (2010): 157-180.

Valdebenito, Alfonso. Historia del periodismo chileno (1812-1955). Santiago de Chile: (s.n.). 1956. 